\title{
Managing acute illness in general practice: measuring arts as well as science
}

As part of the Inquiry into the Quality of General Practice in England, The King's Fund commissioned a research report to examine the management of acute illness. ${ }^{1}$ The report divides acute illness into four groups: acute minor or selflimiting illness; acute major illness that may be self-limiting or require treatment; acute exacerbation of existing major illness; and acute presentation of a new chronic illness.

The focus of the report is on the quality of care provided by GPs, and addresses issues related to all practice staff, telephone consultations, and out-ofhours care. The methodology included literature reviews, discussion with healthcare professionals and users, and review by experts, then culminated in a draft template of quality measures.

Managing acute illness is bread and butter for GPs who manage the majority of acutely ill patients presenting to the NHS. Of the 280 million consultations that occur in general practice in England each year, up to two-thirds are for acute problems. The majority of these problems are managed in primary care but a small proportion requires management in secondary care, ending up as emergency admissions to hospital.

\section{EMERGENCY ADMISSIONS}

This is where the NHS and other health care systems are under pressure as emergency admissions are expensive, cause distress for patients and their families, and cause disruption to the delivery of elective care. ${ }^{2}$ There were over 5 million emergency admissions in England in 2008/2009. ${ }^{3}$ This represents an average increase of $6 \%$ on the previous year and, despite widespread efforts, only a few areas were successful in reducing admissions. ${ }^{4}$

The reason for the increase, which has been consistent over the past 10 years, has been blamed on a reduction in the capacity of general practice to manage acute illness. ${ }^{5}$ However, a more recent report concludes that the rise in emergency admissions cannot be attributed in total to changes in general practice. ${ }^{6}$ The rise has also been caused by, in part, a lowering of the clinical threshold for emergency admissions among secondary care providers. Despite this, it is widely considered that the solution lies with primary care, as better out-of hospital care and preventive care will reduce the risk of admission. ${ }^{7}$

\section{EVALUATION OF ACUTE ILLNESS}

The assessment and management of acutely and potentially seriously ill patients is a core skill of general practice. As The King's Fund report points out, acute minor illness is common in general practice and serious illness is rare. GPs rely on several mechanisms to distinguish the two.

There is little evidence from primary care for the positive predictive value of alarm symptoms or 'red flags' for potentially serious conditions, such as myocardial infarction or cancer. There is also a concern, highlighted in The King's Fund report, but based on findings by the General Medical Council, ${ }^{8}$ that recently qualified doctors in the UK are concerned about their ability to evaluate seriously ill people.

\section{MEASURING QUALITY OF CARE}

Given the importance of the context and the challenges of diagnosing and managing acute illness in general practice, how does The King's Fund report suggest that the quality of care in acute illness be measured? The report identifies nine measures of quality that need to be present in the care of acute illness, these include: good access; sufficient consultation time and facilities to assess the problems; accurate diagnosis; adequate patient information; symptom resolution; appropriate prescribing; costeffective use of resources; patient satisfaction; and appropriate referral.

These measures seem laudable and probably reflect the aims and values of most GPs. However, the authors of The King's Fund report acknowledge that the measures are largely at a developmental stage, as research to support some of them is limited, baseline metrics are not currently available, and the definition of 'high quality' may vary across populations and healthcare economies.

There is some evidence for the effectiveness of significant event analysis and peer review in improving subsequent practice. ${ }^{9}$ However, as further work on developing and refining measures is undertaken, it would also be encouraging to see a focus on patient outcomes, rather than on easier-to-measure, but less relevant, process measures.

\section{APPLICATION OF CONCEPTUAL MEASURES}

The authors of The King's Fund report apply the conceptual measures to a number of aspects of the management of acute illness in general practice. For example, they begin with acute psychological distress, where they suggest that the quality measures may focus on caring, compassion, and empathy. Although difficult to measure and requiring further work, these values were considered important by professional and lay responders in this research. This approach represents a refreshing contrast to the 'admissions avoided' approach of many current performance measures in acute illness care. $^{7}$

Another highlight of the The King's Fund report is the informed use of 
existing data on urgent referrals for possible cancer. By examining the numbers of referrals - the percentage of cancer diagnoses among these referrals, and for general practices overall - a picture emerges of how practices manage patients with acute illness that may be cancer. To support this sort of analysis and explore the implications, the authors of The King's Fund report suggest peer reviewed audit of referral letters and case notes. Of course, the report suggests other measures, such as access to care and prescribing indicators for antibiotics, that are more mainstream and use the rich data routinely available in primary care, but it is the mix of suggested indicators that indicates how grounded the report is in general practice.

\section{CONCLUSION}

Despite the lack of available evidence about the quality of care of acute illness and the fact that this report does not go as far as recommending specific measures, there are real opportunities highlighted for general practice to develop measures that reflect patientcentered care, communication skills, and values that are lost in the bald comparison of admissions or referrals data.
It is perhaps interesting to reflect that one of the few evidence-based interventions to reduce avoidable emergency admissions is continuity of care with a GP. ${ }^{10,11}$ Developing quality measures for acute illness that encourage the development of a relationship between a patient and an experienced, skilled, and trusted GP would surely capitalise on the strengths of general practice and may succeed in reducing referrals and admissions where an increasing diversity of alternative services has failed.

\section{Sarah Purdy,}

Consultant Senior Lecturer in Primary Health Care, University of Bristol, Bristol.

\section{Provenance}

Commissioned; not peer reviewed.

\section{REFERENCES}

1. Jones R, White P, Armstrong D, et al. Managing acute illness. An inquiry into the quality of general practice in England. London: The King's Fund, 2010.

2. Purdy S, Griffin T. Reducing hospital admissions. BMJ 2008; 336(7634): 4-5.

3. The NHS Information Centre. Hospital Episode Statistics. Headline figures 2008-09. http://www.hesonline.nhs.uk/Ease/servlet/ContentServe $r$ siteID=1937\& categoryID=193 (accessed 2 Sep 2010).

4. Gillam S. Rising hospital admissions. BMJ 2010; 340: c636.

5. Saxena S, Bottle A, Gilbert R, Sharland M. Increasing short-stay unplanned hospital admissions among children in England; time trends analysis '97-'06. PLoS
One 2009; 4(10): e7484

6. Blunt I, Bardsley M, Dixon J. Trends in emergency admissions in England 2004-2009: is greater efficiency breeding inefficiency? London: Nuffield Trust, 2010.

7. NHS Institute for Innovation and Improvement. Directory of Ambulatory Emergency Care for Adults. Warwick: NHS Institute for Innovation and Improvement, 2010.

8. General Medical Council. Tomorrow's doctors: outcomes and standards for undergraduate medical education. London: GMC, 2009. http://www.gmcuk.org/TomorrowsDoctors_2009.pdf_27494211.pdf (accessed on 2 Sep 2010).

9. Bowie P, Pope L, Lough M. A review of the current evidence base for significant event analysis. J Eval Clin Pract 2008; 14(4): 520-536.

10. Christakis DA, Mell L, Koepsell TD, et al. Association of lower continuity of care with greater risk of emergency department use and hospitalization in children. Pediatrics 2001; 107(3): 524-529.

11. Menec V, Sirski M, Attawar D, Katz A. Does continuity of care with a family physician reduce hospitalizations among older adults? J Health Serv Res Policy 2006; 11(4): 196-201.

DOI: 10.3399/bjgp10X515656

\section{ADDRESS FOR CORRESPONDENCE}

Sarah Purdy

Consultant Senior Lecturer in Primary

Health Care, University of Bristol,

25 Belgrave Road, Bristol BS8 2AA.

E-mail: Sarah.purdy@bristol.ac.uk 